Research Article

\title{
Experimental Evaluation of the Influence of Early Disturbance on the Performance of Basalt Fiber Concrete
}

\author{
Zhe Huang, Yan Li (iD, Yichen Liu, Fengjie Cai, and Tianyu Liang \\ School of Highway, Chang'an University, Xi'an 710064, China \\ Correspondence should be addressed to Yan Li; liyan@chd.edu.cn
}

Received 27 May 2020; Revised 10 July 2020; Accepted 14 July 2020; Published 31 July 2020

Academic Editor: Peng Zhang

Copyright (C) 2020 Zhe Huang et al. This is an open access article distributed under the Creative Commons Attribution License, which permits unrestricted use, distribution, and reproduction in any medium, provided the original work is properly cited.

\begin{abstract}
By applying early disturbance to the concrete, the influence of the disturbance on the macroscopic mechanical properties of basalt fiber concrete during the period from the initial setting to the final setting is explored, and the influence mechanism is revealed. Also, the influence of this disturbance on the process of sulfate erosion of concrete is evaluated by the sulfate erosion test and by the ultrasonic data acquisition of its damage process. The experimental results show that the flexural strength of basalt fiber concrete is increased after the concrete has been disturbed in the early stage of condensation but is decreased in the middle stage of condensation and is not affected in the later stage. When the condensation and hardening processes are disturbed, damage is caused inside the concrete, which is greater with the increase in the condensation degree until the penetration resistance reaches about $15 \mathrm{MPa}$, which then is more and more reduced. The durability of basalt fiber concrete is reduced by disturbance, which has a significant effect on it when the penetration resistance is between $7 \mathrm{MPa}$ and $16 \mathrm{MPa}$.
\end{abstract}

\section{Introduction}

Concrete materials demonstrate excellent compressive performance, but the tensile strength is only $1 / 10$ of its compressive strength, which is unfavorable to the concrete in the tensile zone of the structure [1-3]. Addition of fiber can much improve this defect. There are many kinds of fibers often used in concretes, such as steel fiber, carbon fiber, glass fiber, cellulose fiber, polypropylene fiber, and polyvinyl acetate (PVA) fiber $[4,5]$. The addition of fiber can improve the strength and durability of concrete, prolong its service life, and adapt to complex environment [6-8]. In the early stage of condensation and hardening, since the cement hydration process has not been completed, the strength and bonding properties of concrete continue to change with the age of it, and the structural properties of concrete also keep changing. Therefore, the concrete structure in the early age is essentially different from that in the normal use stage $[9,10]$. As a heterogeneous mixed material, the performance of hardened concrete depends on its early microstructure formation process [11]. In order to ensure the overall progress and continuity of the project, blasting excavation and impact piling are often carried out in parallel with the concrete pouring construction, resulting in inevitable construction vibration around the concrete structure, and we call it disturbance $[12,13]$. Before the concrete is finally set, its internal microstructure has not been fully formed, and the concrete is very sensitive to the influence of external disturbances. Disturbance causes tensile stress inside the concrete, resulting in microcracks that cannot be closed $[14,15]$. The presence of these microcracks will provide an intrusive channel for corrosive media, which not only directly affects the aesthetics of building decoration but affects the durability and working life. Compared with ordinary concrete, the tensile strength and ultimate elongation of fiber concrete are improved $[16,17]$. Studies show that addition of fibers significantly improves the early plastic cracking, antiabrasion, and impact resistance of mortar and concrete [18]. Fiber has a significant effect on the crack resistance of cement concrete. The chaotic support system formed by the fibers in concrete produces an effective reinforcement effect, which greatly improves the crack resistance of concrete [19].

Basalt fiber is a new type of concrete reinforced material. It has the advantages of high cost performance, high tensile 
strength, anticorrosion, high temperature resistance, and good crack resistance, which make it an ideal substitute for other fiber materials [20-22]. At present, the research on basalt fiber in the field of civil engineering is mainly focused on the mechanical properties of basalt fiber concrete, but the influence of disturbance on basalt fiber concrete is rarely studied [23]. Therefore, systematic research on the impact of disturbance on the performance of early basalt concrete is of important theoretical and practical value to the analysis and control of early disturbance safety during the construction period of fiber-reinforced concrete structures.

\section{Test Materials and Methods}

\subsection{Test Material and Specimen Preparation}

2.1.1. Test Material. The cement used in the test was $\mathrm{P} \bullet \mathrm{O}$ $42.5 \mathrm{R}$ cement, and the performance indices are shown in Table 1. Natural river sand was adopted as fine aggregate, whose fineness modulus was 2.9, and apparent density was $2650 \mathrm{~kg} / \mathrm{m}^{3}$. Crushed limestone was taken as coarse aggregate, which was continuously graded from 5 to $25 \mathrm{~mm}$, with an apparent density of $2690 \mathrm{~kg} / \mathrm{m}^{3}$. The physical and mechanical property indices of basalt fiber used are shown in Table 2. When preparing concrete, in order to save cement, improve the workability of the mixture, or reduce the watercement ratio to increase the concrete strength level, a certain amount of water-reducing agent is often added. Polycarboxylic acid water-reducing agent was used as the waterreducing agent, whose water-reducing rate was 25\% (mass fraction).

\subsubsection{Mix Ratio Determination and Specimen Preparation.} Volume method and mass method are often employed to determine the concrete mix ratio, among which the volume method is the most common [24]. In order to make concrete meet the requirements of strength grade, workability, durability, and economic application, the concrete mix ratio should be designed with careful selection of raw materials according to specific requirements and reasonable determination of the proportion of each component [25]. The strength grade of the concrete used in this test was C40, and according to the information provided by the manufacturer, the dosage of water-reducing agent was $4 \%$ of the cementing material. According to the mix ratio experiment, the specific proportion is shown in Table 3. The slump of the newly mixed concrete measured 130-150 mm.

There are generally two preparation processes for basalt fiber concrete: the direct fiber incorporation method and the pretreatment fiber incorporation method. Studies have shown that the incorporation of basalt fibers will have a greater impact on the internal structure of concrete [26]. The mechanical properties of the pretreatment fiber incorporation method are significantly higher than the direct fiber incorporation method. The former can make the fibers well dispersed in the concrete, enhance the adhesion between the fibers and the concrete, and thus improve the performance of the concrete matrix, so the pretreatment fiber incorporation method is used. In the experiment, stones and sand were first put in order and mixed dry for $60 \mathrm{~s}$; then, cement and water were added and mixed for $30 \mathrm{~s}$. At the same time, the fiber was evenly spread into the mixer, and then, the weighing water reducer was added and mixed for $2 \mathrm{~min}$. The fresh concrete is mixed evenly, without segregation and bleeding, and the workability is good. Put the fresh concrete into the mold and use a shovel to insert the mold when entering the mold. After entering the mold, smoothen the surface with a shovel and vibrate on the shaker for $5 \mathrm{~s}$ to make the concrete fully dense.

This experiment formed two kinds of specimens of different sizes: a cube specimen of $100 \mathrm{~mm} \times 100 \mathrm{~mm} \times 100 \mathrm{~mm}$ for the compressive strength test and sulfate corrosion durability test and a prism specimen of $100 \mathrm{~mm} \times 100 \mathrm{~mm} \times 400 \mathrm{~mm}$ for the flexural strength test and ultrasonic testing.

\subsection{Test Process and Method}

2.2.1. Determination of Condensation Time. Since the research object was the concrete which was between the initial setting and the final setting and did not totally meet hardening standards, the initial setting and final setting of the concrete needed to be measured and analyzed before the disturbance test started. The setting time of concrete was measured by the method of penetration resistance, referring to the setting time test in GBT50080-2016 [27], and the penetration resistance was calculated as follows:

$$
f_{\mathrm{PR}}=\frac{P}{A}
$$

where $f_{\mathrm{PR}}$ is the penetration resistance, $\mathrm{MPa} ; P$ is the penetration pressure, $\mathrm{N}$; and $A$ is the stylus area, $\mathrm{mm}^{2}$; calculation was accurate to $0.1 \mathrm{MPa}$.

Setting time was determined by the drawing fitting method. With the penetration resistance as the ordinate and time as the abscissa (accurate to $1 \mathrm{~min}$ ), the relationship between penetration resistance and time was plotted. After two straight lines parallel to the abscissa with $3.5 \mathrm{MPa}$ and $28 \mathrm{MPa}$ were drawn, the abscissa of the two intersections that intersected the curve showed the initial and final setting times of the concrete mixture.

2.2.2. Disturbance Test and Ultrasonic Testing. When concrete is between the initial setting stage and the final setting stage, the disturbance has the greatest impact on its performance. Therefore, the disturbed period was determined between the initial and the final setting stages [28]. According to the influence of different disturbance forms on concrete performance in the actual project and the relevant literature [29-32], the DC-1000-15 horizontal electric vibration table was selected to provide the disturbance, with the frequency being $15 \mathrm{~Hz}$, the maximum vibration speed $37.7 \mathrm{~cm} / \mathrm{s}$, the amplitude $4 \mathrm{~mm}$, and the vibration forms sinusoidal vibration. The vibration started from the initial setting of cement mortar and was distributed in the whole process of cement mortar condensation. The vibration duration of each group was $40 \mathrm{~min}$. 
TABle 1: Chemical composition and properties of $\mathrm{P} \bullet \mathrm{O} 42.5 \mathrm{R}$ cement.

\begin{tabular}{|c|c|c|c|c|c|c|c|}
\hline \multirow[t]{2}{*}{ Initial setting time $(\mathrm{h} / \mathrm{min})$} & \multirow[t]{2}{*}{ Final setting time $(\mathrm{h} / \mathrm{min})$} & \multicolumn{2}{|c|}{ Stability $(\mathrm{mm})$} & \multicolumn{2}{|c|}{$\begin{array}{l}\text { Flexural strength } \\
\qquad(3 \mathrm{~d})(\mathrm{MPa})\end{array}$} & \multicolumn{2}{|c|}{$\begin{array}{l}\text { Compressive } \\
\text { strength }(3 \mathrm{~d}) \\
(\mathrm{MPa})\end{array}$} \\
\hline & & Standard & Test & Standard & Test & Standard & Test \\
\hline $2 / 45$ & $3 / 51$ & $\leq 5.0$ & 0.5 & $\geq 21.0$ & 30.6 & $\geq 42.5$ & 54.6 \\
\hline
\end{tabular}

TABLE 2: Physical and mechanical properties of basalt fiber.

\begin{tabular}{lcccc}
\hline Length $/ \mathrm{mm}$ & Density $\left(\mathrm{kg} / \mathrm{m}^{3}\right)$ & Tensile modulus $(\mathrm{GPa})$ & Tensile strength $(\mathrm{MPa})$ & Elongation at break $(\%)$ \\
\hline 18 & 2650 & $93-110$ & $4150-4800$ & 3.1 \\
\hline
\end{tabular}

TABle 3: Concrete mix ratio $\left(\mathrm{kg} / \mathrm{m}^{3}\right)$.

\begin{tabular}{lcccccc}
\hline Cement & Sand & Gravel & Water & Water-cement ratio & Sand rate & Water-reducing agent \\
\hline 420 & 760 & 1040 & 176 & 0.42 & 0.42 & 16.8 \\
\hline
\end{tabular}

After curing for $7 \mathrm{~d}$ and $28 \mathrm{~d}$, the disturbed specimens were subjected to ultrasonic nondestructive testing by an NM-4A nonmetal ultrasonic detection analyzer to detect whether the defects in the concrete were increased due to disturbance, as shown in Figure 1. The test principle was that when the wave transmits in concrete, it will encounter various medium defects and its transmission direction and path will inevitably change, so the energy of the wave at the defects will be attenuated. As sound time, amplitude, and frequency change, velocity, time, and amplitude change too [33]. After mold removal, the specimens were cured in water for $7 \mathrm{~d}$ and $28 \mathrm{~d}$, and then, they were, respectively, conducted ultrasonic testing. Before the test, the specimens were kept dry to avoid the influence of water content on the test results. The average value of three measured data of a sample was taken to be compared with that of the undisturbed sample, and then, the damage degree was calculated [34].

\subsubsection{Concrete Compression and Flexural Test. Considering} the limitations of a single evaluation method, the influence of early disturbance on the macroscopic mechanical properties of concrete was comprehensively evaluated by indices such as compressive strength, flexural strength, and damage degree. When the test piece reached the age of $28 \mathrm{~d}$, its surface was wiped clean and dry so that compression and flexural tests referring to GBT50080-2016 could be carried out. When compressive strength of concrete was being measured, the loading speed during the test operation was set $0.5-0.8 \mathrm{MPa}$ per second in order to make the data reliable. A $100 \mathrm{kN}$ universal material testing machine was used as the flexural test equipment. When the test was being conducted, the side of the test piece was used as the loadbearing surface. The descending speed of the press head was controlled to $0.5 \mathrm{~mm}$ per minute when loading.

2.2.4. Sulfate Corrosion Test. The properties and microstructure of concrete are the direct factors affecting the durability of structural engineering, and the erosion of concrete by sulfate is one of the important factors causing the damage and destruction to concrete [35]. Early disturbed concrete will inevitably be exposed to sulfate erosion environment in the service process. Therefore, the early disturbed concrete after being hardened was subjected to the dry-wet cycle sulfate erosion test to explore the deterioration degree of the disturbed concrete by sulfate erosion with measurement of mass change rate and ultrasonic testing. The test was conducted with reference to GBT 50082-2009 "sulfate dry-wet cycle test" [36]. Considering the effect of concentration on the erosion mechanism and according to the related literature, sodium sulfate solution was used as the erosion medium in this experiment, with the solution mass fraction being 7\% [37-40]. When reaching $2 \mathrm{~d}$ before the predetermined age, the specimen was taken out of the standard curing box, wiped until its surface was dry, and put into the oven. After being dried, the specimen was cooled to room temperature in a dry environment and then put into the sulfate dry-wet cycling machine for test. After this test, the mass of each sample was detected, and ultrasonic detection was conducted every ten cycles.

\section{Analysis of Test Results}

3.1. Concrete Setting Time. The development of concrete penetration resistance was first studied, and the condensation and hardening processes were divided into three stages. It was defined that when the penetration resistance was $0 \sim 3.5 \mathrm{MPa}$, the concrete was in the initial stage of condensation and hardening; when the penetration resistance value was $3.5 \sim 28 \mathrm{MPa}$, the concrete was in the intermediate stage of condensation and hardening; and when the penetration resistance was greater than $28 \mathrm{MPa}$, the concrete was in the later stage of condensation and hardening. The resulting data are shown in Figure 2.

The fitting function equation is

$$
y=0.0173 \times 1.0125^{x}
$$

According to the method of setting time fitting, the initial setting time of basalt fiber concrete was $430 \mathrm{~min}$ and the final setting time was $640 \mathrm{~min}$. After the initial setting time had been determined, vibration was carried out, which started exactly from it. The two specimens were, respectively, 


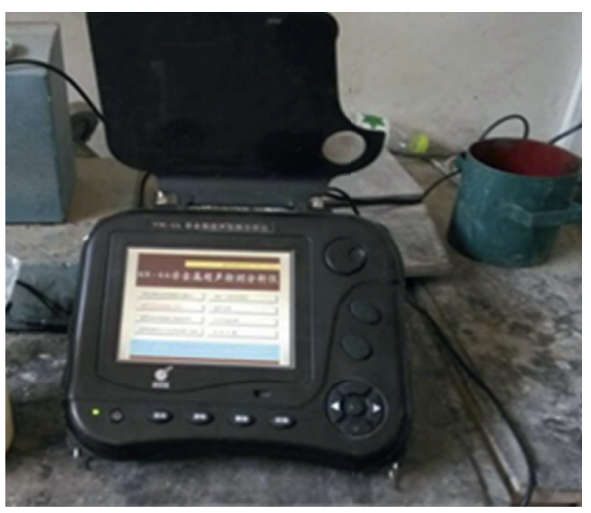

(a)

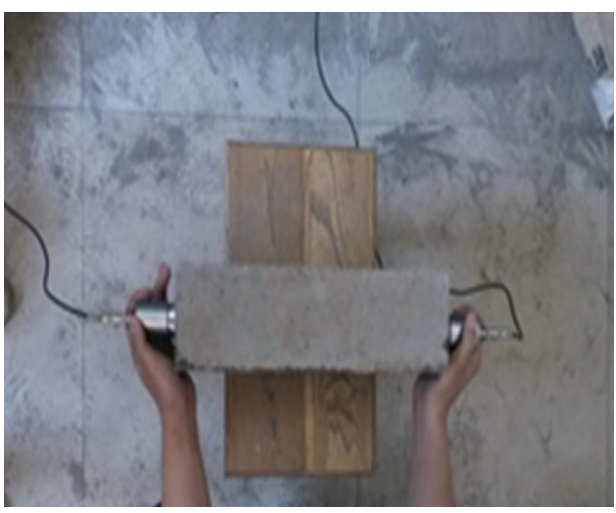

(b)

FIGURE 1: NM-4A nonmetal ultrasonic detection analyzer.

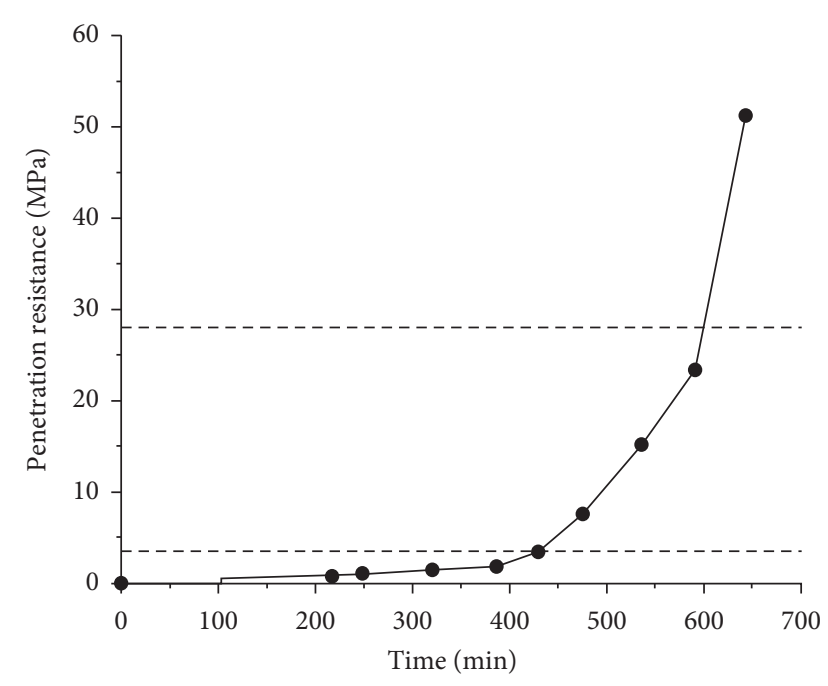

FIgURE 2: Curve of penetration resistance-time.

disturbed at different time periods until all the specimens were completely disturbed.

\subsection{Influence of Disturbance on the Strength of Basalt Fiber Concrete}

3.2.1. Influence of Disturbance on the Flexural Strength of Basalt Fiber Concrete. Twelve specimens were prepared by five perturbations between the initial setting and the final setting of concrete. They were divided into six groups, two for each group, and numbered, respectively. The flexural test data of basalt fiber concrete and plain concrete are shown in Tables 4 and 5 .

It can be seen from Figure 3 that the flexural strength of basalt fiber concrete has been significantly improved by disturbing the concrete specimen before the initial setting of cement mortar. As the concrete hardens, the disturbance has a significant negative effect on the basalt fiber flexural strength. Since the setting time is about $400 \mathrm{~min}$, the disturbance makes the flexural strength of the fiber concrete decrease significantly. When the penetration resistance is $7.4 \mathrm{MPa}$, the basalt fiber concrete is vibrated, and its flexural strength reaches the lowest.
Therefore, it can be seen that the flexural strength of basalt fiber concrete can be significantly improved by disturbing the concrete before the initial setting. After the initial setting, the flexural strength of basalt fiber concrete is greatly reduced by disturbance. When basalt fiber concrete is disturbed near the final setting, the effect of the compressive strength decreases gradually. In addition, the flexural strength of basalt fiber concrete is slightly higher than that of plain concrete.

This phenomenon is closely related to the bond degree of aggregate, fiber, and gelling material. After the initial setting, the bonds between the materials have been formed, which make the concrete lose its plasticity, but vibrance will disturb the newly formed bonds and separate them. Therefore, after the disturbance, the condensation continues to be not much affected. As a result, during the disturbed time, the flexural strength loss is small. With the development of condensation and hardening, more and more connection bonds are formed, so the damage grows greater after the disturbance is caused. In the later stage of condensation, due to the formation of the bonds, the plastic loss reaches a certain stage, and the impact of the compressive strength decreases gradually.

\subsubsection{Influence of Disturbance on the Compressive Strength of} Basalt Fiber Concrete. The test process was the same as above. The basalt fiber concrete and plain concrete compressive test data are shown in Tables 6 and 7 .

Tables 6 and 7 can be used to make a broken line graph, as shown in Figure 4.

As can be seen from Figure 4, the compressive strength of basalt fiber concrete and plain concrete first increases and then decreases with the increase in penetration resistance after disturbance, and the compressive strength increases most obviously before condensation. This is because in the early stage of condensation, the connection between the aggregate and cementitious material has not yet been formed and is in a separated state, and the fiber concrete is in the plastic stage. Disturbance makes the fiber, coarse and fine aggregates, and cementitious material fully combined so that the various interfaces in the later stage of condensation and hardening are fully combined, thereby enhancing the compressive strength. 
TABLE 4: Flexural data of basalt fiber concrete.

\begin{tabular}{|c|c|c|c|c|c|}
\hline Number & Maximum force $(\mathrm{kN})$ & Flexural strength $(\mathrm{MPa})$ & Average (MPa) & Vibration time (min) & Penetration resistance $(\mathrm{MPa})$ \\
\hline G0-1 & 14.910 & 6.150 & \multirow{2}{*}{6.301} & \multirow{2}{*}{0} & \multirow{2}{*}{0} \\
\hline G0-2 & 15.670 & 6.452 & & & \\
\hline G1-1 & 15.692 & 8.062 & \multirow{2}{*}{8.011} & \multirow{2}{*}{40} & \multirow{2}{*}{1.82} \\
\hline G1-2 & 17.020 & 7.959 & & & \\
\hline G2-1 & 14.010 & 6.305 & \multirow{2}{*}{5.911} & \multirow{2}{*}{40} & \multirow{2}{*}{3.4} \\
\hline G2-2 & 12.260 & 5.517 & & & \\
\hline G3-1 & 10.240 & 5.608 & \multirow{2}{*}{5.432} & \multirow{2}{*}{40} & \multirow{2}{*}{7.6} \\
\hline G3-2 & 13.900 & 5.256 & & & \\
\hline G4-1 & 12.450 & 5.603 & \multirow{2}{*}{5.736} & \multirow{2}{*}{40} & \multirow{2}{*}{15.27} \\
\hline G4-2 & 13.040 & 5.868 & & & \\
\hline G5-1 & 18.020 & 6.509 & \multirow{2}{*}{6.399} & \multirow{2}{*}{40} & \multirow{2}{*}{23.4} \\
\hline G5-2 & 16.200 & 6.290 & & & \\
\hline
\end{tabular}

TABLE 5: Flexural data of plain concrete.

\begin{tabular}{|c|c|c|c|c|}
\hline Penetration resistance $(\mathrm{MPa})$ & Vibration time (min) & Number & Flexural strength $(\mathrm{MPa})$ & Average $(\mathrm{MPa})$ \\
\hline \multirow[t]{2}{*}{0} & \multirow[t]{2}{*}{0} & A0-1 & 5.278 & \multirow{2}{*}{5.558} \\
\hline & & $\mathrm{A} 0-2$ & 6.838 & \\
\hline \multirow{2}{*}{1.82} & \multirow{2}{*}{40} & A1-1 & 6.858 & \multirow{2}{*}{6.377} \\
\hline & & A1-2 & 5.895 & \\
\hline \multirow{2}{*}{3.4} & \multirow{2}{*}{40} & A2-1 & 4.514 & \multirow{2}{*}{4.723} \\
\hline & & A2-2 & 4.932 & \\
\hline \multirow{2}{*}{7.6} & \multirow{2}{*}{40} & A3-1 & 4.740 & \multirow{2}{*}{5.116} \\
\hline & & A3-2 & 5.492 & \\
\hline \multirow{2}{*}{15.27} & \multirow{2}{*}{40} & A4-1 & 6.467 & \multirow{2}{*}{6.253} \\
\hline & & A4-2 & 6.039 & \\
\hline \multirow{2}{*}{23.4} & \multirow{2}{*}{40} & A5-1 & 5.371 & \multirow{2}{*}{5.043} \\
\hline & & A5-2 & 4.715 & \\
\hline
\end{tabular}

According to Tables 4 and 5, graphs can be drawn, as shown in Figure 3.

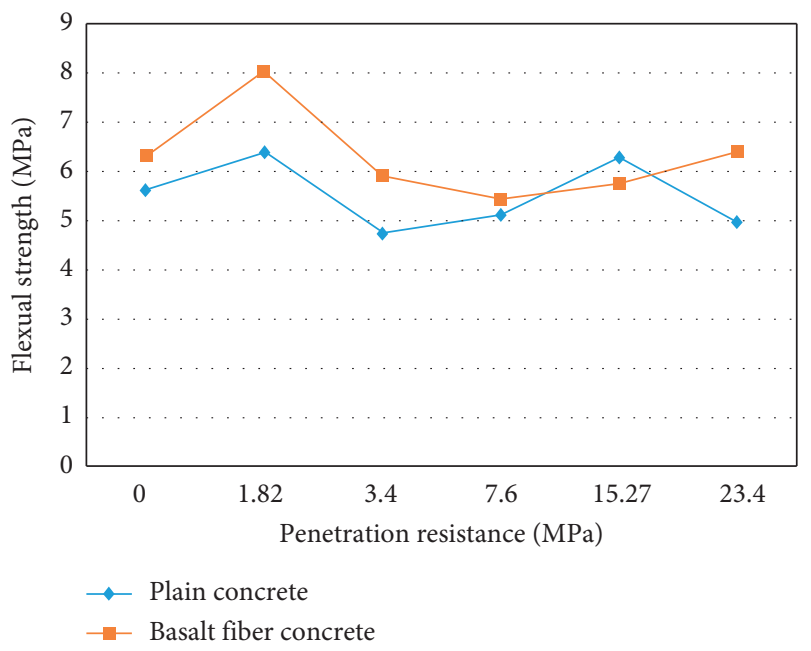

FIgURE 3: Comparison of flexural strength of plain concrete and basalt fiber concrete.

When the penetration resistance is $7 \sim 16 \mathrm{MPa}$, the disturbance has a negative effect on the flexural strength of the two kinds of concrete, while the fiber concrete is less affected. The influence of disturbance on the compressive strength of basalt fiber concrete and plain concrete is reduced when the final setting is near. The influence trend of disturbance on the two kinds of concrete is basically the same.

3.3. Influence of Disturbance on Internal Damage of Basalt Fiber Concrete. There is a certain correlation between ultrasonic wave velocity and concrete strength, which can be used to reflect the internal microscopic damage of concrete. In order to quantitatively analyze the internal damage of concrete, the relative value of ultrasonic wave velocity attenuation is defined as concrete damage degree $D[41]$, and $D$ is calculated as follows:

$$
D=1-\left(\frac{V_{t}}{V_{0}}\right)^{2}
$$

where $V_{t}$ is the ultrasonic wave velocity of disturbed concrete, $\mathrm{km} / \mathrm{s}$, and $V_{0}$ is the ultrasonic wave velocity of undisturbed concrete, $\mathrm{km} / \mathrm{s}$.

The graphs of ultrasonic data are shown in Figures 5 and 6.

As shown in the figures, disturbance at any time during the whole coagulation process causes damage, but the damage degree is different at different periods. At the initial stage of condensation, the basalt fiber concrete is in the plastic stage, and not so many connection bonds are formed. The connection between basalt fiber, aggregate, and cementitious material is damaged by disturbance. However, 
TABLE 6: Compressive data of basalt fiber concrete.

\begin{tabular}{|c|c|c|c|c|}
\hline Number & Compressive strength (MPa) & Average $(\mathrm{MPa})$ & Vibration time (min) & Penetration resistance $(\mathrm{MPa})$ \\
\hline $\begin{array}{l}\mathrm{G} 0-1 \\
\mathrm{G} 0-2\end{array}$ & $\begin{array}{l}36.332 \\
36.684\end{array}$ & 36.513 & 0 & 0 \\
\hline $\begin{array}{l}\text { G1-1 } \\
\text { G1-2 } \\
\end{array}$ & $\begin{array}{l}37.410 \\
37.432 \\
\end{array}$ & 37.421 & 40 & 1.82 \\
\hline $\begin{array}{l}\text { G2-1 } \\
\text { G2-2 }\end{array}$ & $\begin{array}{l}38.124 \\
36.656 \\
\end{array}$ & 36.885 & 40 & 3.4 \\
\hline $\begin{array}{l}\text { G3-1 } \\
\text { G3-2 }\end{array}$ & $\begin{array}{l}35.162 \\
34.332\end{array}$ & 34.752 & 40 & 7.6 \\
\hline $\begin{array}{l}\text { G4-1 } \\
\text { G4-2 } \\
\end{array}$ & $\begin{array}{l}35.940 \\
35.042 \\
\end{array}$ & 35.491 & 40 & 15.27 \\
\hline $\begin{array}{l}\text { G5-1 } \\
\text { G5-2 }\end{array}$ & $\begin{array}{l}37.854 \\
36.624 \\
\end{array}$ & 36.024 & 40 & 23.4 \\
\hline
\end{tabular}

TABLE 7: Compressive data of plain concrete.

\begin{tabular}{|c|c|c|c|c|}
\hline Penetration resistance $(\mathrm{MPa})$ & Vibration time (min) & Number & Compressive strength $(\mathrm{MPa})$ & Average $(\mathrm{MPa})$ \\
\hline \multirow{2}{*}{0} & \multirow{2}{*}{0} & $\mathrm{~A} 0-1$ & 35.361 & \multirow{2}{*}{35.129} \\
\hline & & $\mathrm{A} 0-2$ & 34.897 & \\
\hline \multirow{2}{*}{1.82} & \multirow{2}{*}{40} & A1-1 & 36.213 & \multirow{2}{*}{37.079} \\
\hline & & A1-2 & 37.945 & \\
\hline \multirow{2}{*}{3.4} & \multirow{2}{*}{40} & A2-1 & 36.676 & \multirow{2}{*}{36.431} \\
\hline & & A2-2 & 36.185 & \\
\hline \multirow{2}{*}{7.6} & \multirow{2}{*}{40} & A3-1 & 33.294 & \multirow{2}{*}{34.585} \\
\hline & & A3-2 & 35.875 & \\
\hline \multirow{2}{*}{15.27} & \multirow{2}{*}{40} & A4-1 & 34.070 & \multirow{2}{*}{33.856} \\
\hline & & A4-2 & 33.641 & \\
\hline \multirow{2}{*}{23.4} & \multirow{2}{*}{40} & A5-1 & 34.723 & \multirow{2}{*}{34.959} \\
\hline & & A5-2 & 35.194 & \\
\hline
\end{tabular}

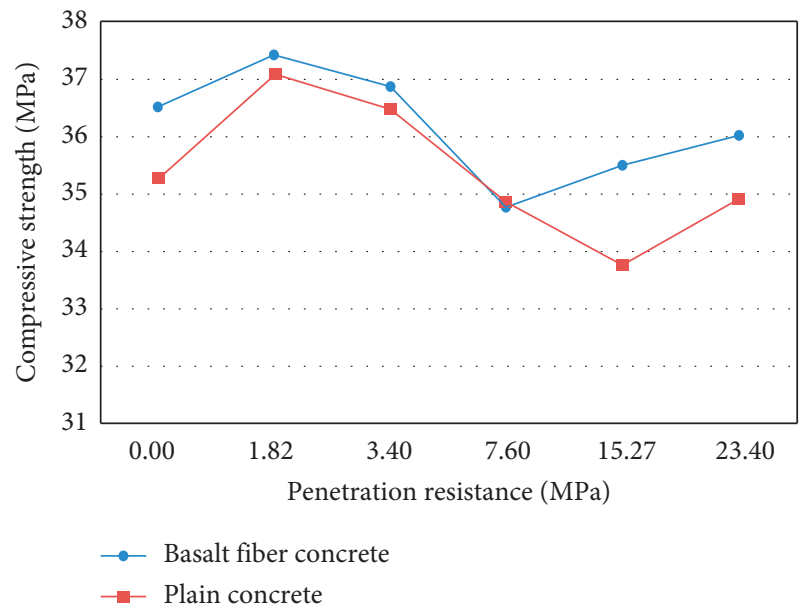

Figure 4: Comparison of compressive strength of plain concrete and of basalt fiber concrete.

after disturbance is stopped, the basalt fiber concrete is still in the plastic stage or has just lost its plasticity, which can be reformed later. When the penetration resistance reaches 3.4 MPa, which marks the initial setting, the concrete is disturbed to minimize the damage. The disturbance in the middle stage of condensation has the greatest damage to concrete. Because the connection between the materials is smaller at this time and the connection is more and more difficult to form after the disturbance is stopped, the influence of the disturbance increases. As the condensation progresses, the plastic phase is nearing its end and brittleness appears. The bonds between aggregate, cementitious material, and fiber are great, and the influence of disturbance on concrete decreases gradually in the late stage of condensation. It can be seen from the graphs that the damage degree of basalt fiber concrete cured for $7 \mathrm{~d}$ is obviously higher than that cured for $28 \mathrm{~d}$.

3.4. Influence of Disturbance on Durability of Basalt Fiber Concrete. Ultrasonic detection and mass loss measurement were performed after cyclic immersion of sulfate solution. The mass change rate is used to measure the quality change in corroded concrete. The mass change rate is defined as the ratio of the mass change in the disturbed concrete specimen when it is eroded to a certain age to the mass before erosion, which is calculated according to the following formula, and the test data obtained are shown in Figures 7 and 8:

$$
K_{m}=\frac{\left(m_{n}-m_{0}\right)}{m_{0}}
$$

where $K_{m}$ is the mass change rate of the specimen after $n$ days of erosion, $\% ; m_{0}$ is the mass of specimen before 


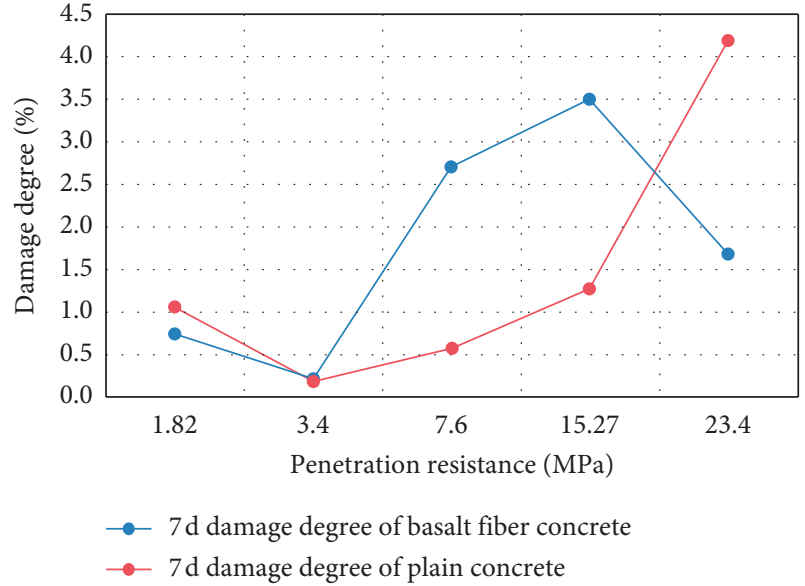

FIgURE 5: Damage degree of basalt fiber concrete and plain concrete for $7 \mathrm{~d}$.

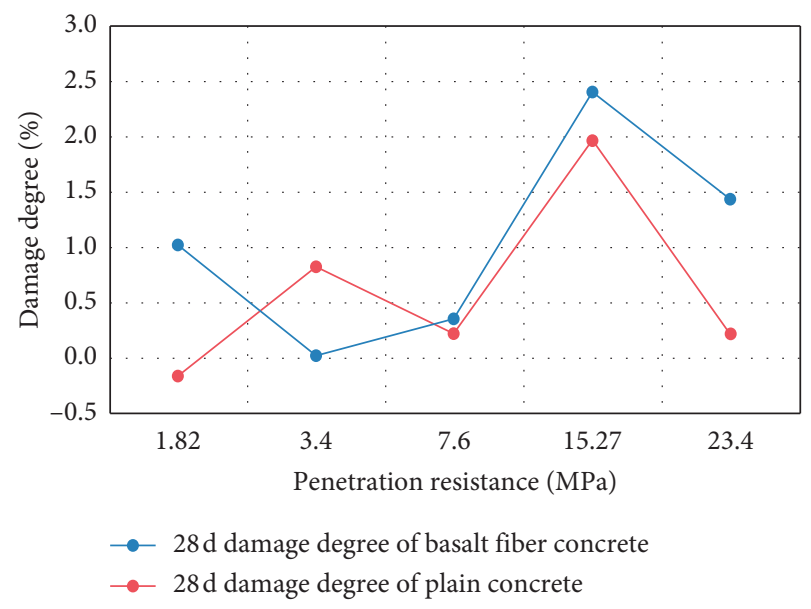

Figure 6: Damage degree of basalt fiber concrete and plain concrete for $28 \mathrm{~d}$.

erosion, $\mathrm{kg}$; and $m_{n}$ is the mass of the specimen after $n$ days of erosion, $\mathrm{kg}$.

As can be seen from Figure 7, with the increase in cycle times, the damage caused by basalt fiber concrete also increases, and the damage of disturbed specimens is greater than that of undisturbed specimens. On the whole, the internal defects and damage are greatest after disturbing the basalt fiber concrete in the middle stage of condensation and soaking it in sulfate solution. This is because in the beginning, the components in the basalt fiber concrete react with the sulfate and produce condensate, which increases the mass of the specimen. After the cycle of soaking, the fiber concrete is eroded and starts to peel off, so the mass becomes smaller. Before and after the initial setting and the final setting, the quality of the specimens changes slowly and the durability is not affected. When the penetration resistance is between 7 and $15 \mathrm{MPa}$, the quality of basalt fiber concrete varies greatly, and the corrosion resistance decreases obviously.

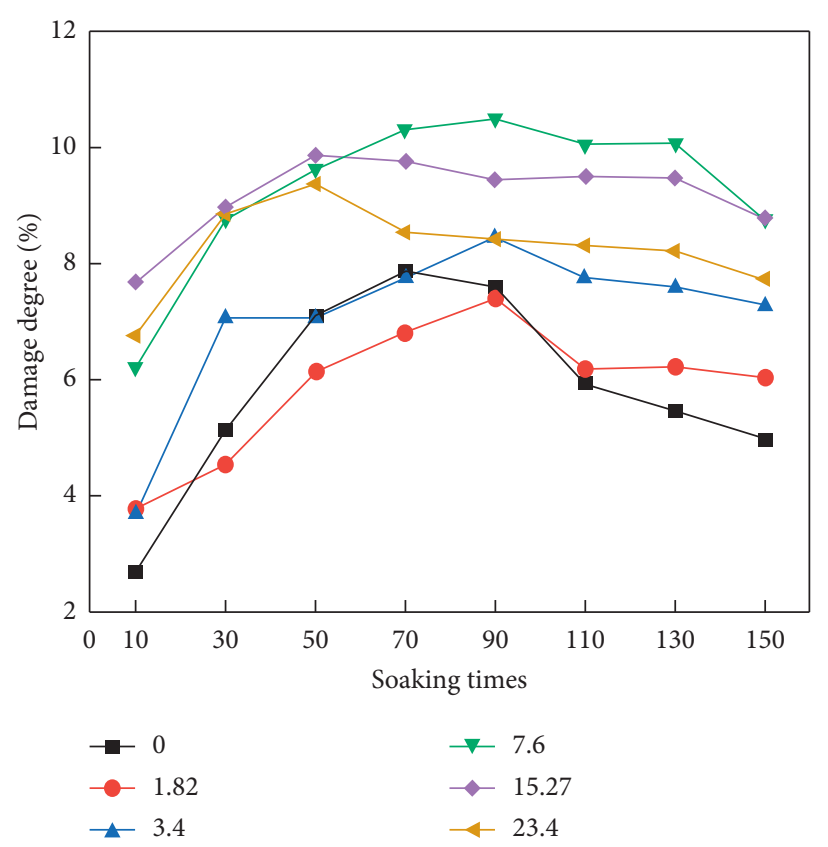

Figure 7: Basalt fiber concrete resistance to sulfate corrosion.

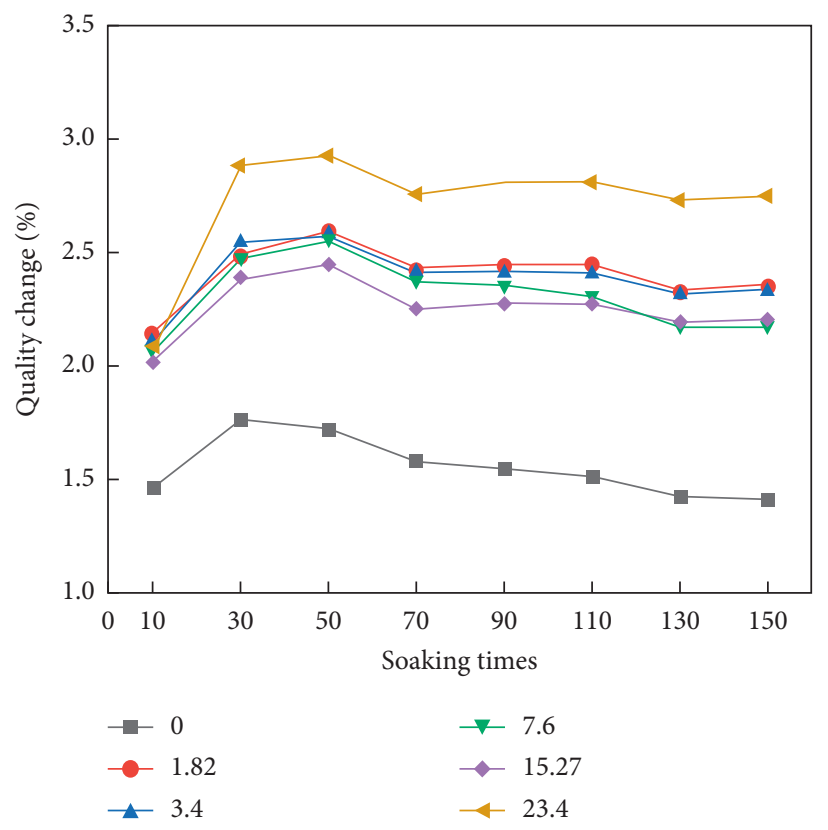

Figure 8: Quality change.

\section{Conclusions}

By disturbing the basalt fiber concrete and investigating the influence of basalt fiber on the macroscopic mechanical properties of the disturbed concrete, this paper establishes the relationship between the microscopic strengthening mechanism and the macroscopic mechanical properties of basalt fiber concrete. The main conclusions are as follows: 
(1) A variety of comparative tests show that the mechanical and antidisturbance properties of basalt fiber concrete are superior to that of plain concrete. This finding can be used in engineering practice to increase the safety and stability of concrete by adding basalt fiber.

(2) The flexural strength of basalt fiber concrete is about $21 \%$ lower, and its compressive strength is about $5 \%$ lower than that of undisturbed specimens when the concrete is disturbed in the middle stage of condensation. During the period of condensation, the bending strength and compressive strength first increase and then decrease with time. In addition, the flexural strength of basalt fiber concrete is greatly improved due to the disturbance from the early stage of condensation to the initial setting, but the disturbance has little effect on the compressive strength of the basalt fiber concrete.

(3) In the early stage of condensation, the internal damage of basalt fiber concrete is relatively small and the damage degree is small too. In the middle stage of condensation, the damage degree of basalt fiber first increases and then decreases, and the damage degree caused by the disturbance after the final setting is quite small.

(4) The durability of basalt fiber concrete is reduced by disturbance. Before and after the initial setting and the final setting, the quality of the specimens changes slowly and the durability is not affected. When the penetration resistance is between 7 and $15 \mathrm{MPa}$, the quality of basalt fiber concrete varies greatly, and the corrosion resistance decreases obviously.

\section{Data Availability}

The data used to support the findings of this study are available from the corresponding author upon request.

\section{Conflicts of Interest}

The authors declare that there are no conflicts of interest.

\section{Acknowledgments}

This study was supported by the China Postdoctoral Science Foundation (no. 2017M620434), Shaanxi Postdoctoral Grant Program (no. 2017BSHYDZZ17), and the Special Fund for Basic Scientific Research of Central College of Chang'an University (no. 310821173501). The authors gratefully acknowledge their financial support.

\section{References}

[1] Y. L. Hu and P. W. Gao, "Study on mechanical properties of rubber concrete with different substitution rates," Journal of Building Materials, vol. 1, pp. 85-92, 2020.

[2] W. Li and J. Xu, "Mechanical properties of basalt fiber reinforced geopolymeric concrete under impact loading,"
Materials Science and Engineering: A, vol. 505, no. 1-2, pp. 178-186, 2009.

[3] H. Y. Zhou and H. Y. Liu, "Study on the mechanism of fatigue compressive damage of concrete and its size effect," Concrete, vol. 12, pp. 1-5, 2019.

[4] P. Zhang and Q.-f. Li, "Effect of polypropylene fiber on durability of concrete composite containing fly ash and silica fume," Composites Part B: Engineering, vol. 45, no. 1, pp. 1587-1594, 2013.

[5] A. Babar and A. Q. Liaqat, "Influence of glass fibers on mechanical and durability performance of concrete with recycled aggregates," Construction and Building Materials, vol. 228, 2019.

[6] P. Zhang, Q. Li, J. Wang, Y. Shi, Y. Zheng, and Y. Ling, "Effect of nano-particle on durability of polyvinyl alcohol fiber reinforced cementitious composite," Science of Advanced Materials, vol. 12, no. 2, pp. 249-262, 2020.

[7] G. W. Li, "Application of basalt fiber in hydraulic erosion resistant high-performance concrete," Concrete, vol. 11, pp. 77-79, 2008.

[8] Y. F. Ling, P. Zhang, and J. Wang, "Effect of sand size on mechanical performance of cement-based composite containing PVA fibers and nano-SiO 2 ," Materials, vol. 13, no. 2, pp. 1-14, 2020.

[9] H. M. Pan and Q. X. Zhao, "Progress in the study of early age concrete," Bulletin of the Chinese Ceramic Society, vol. 1, pp. 64-70, 2017.

[10] E. R. Grist, K. A. Paine, A. Heath, J. Norman, and H. Pinder, "Structural and durability properties of hydraulic lime-pozzolan concretes," Cement and Concrete Composites, vol. 62, pp. 212-223, 2015.

[11] S.-H. Han, W.-S. Park, and E.-I. Yang, "Evaluation of concrete durability due to carbonation in harbor concrete structures," Construction and Building Materials, vol. 48, pp. 1045-1049, 2013.

[12] N. H. P. Para and P. T. Haybale, "Early-strength development of blended concrete under different curing conditions," Emerging Materials Research, vol. 9, no. 1, pp. 59-64, 2020.

[13] P. Zhang, Q. F. Li, and Y. Z. Chen, "Durability of steel fiberreinforced concrete containing $\mathrm{SiO}_{2}$ nano-particles," Materials, vol. 12, no. 13, 2019.

[14] W. Shen, C. Zhang, X. Li, H. Shi, G. Wang, and X. Tian, "Low carbon concrete prepared with scattering-filling coarse aggregate process," International Journal of Concrete Structures and Materials, vol. 8, no. 4, pp. 309-313, 2014.

[15] Y. H. Man and B. K. Sung, "Effects of concrete strength on structural behavior of holed-incrementally prestressed concrete (H-IPC) girder," Advances in Concrete Construction, vol. 3, no. 2, pp. 113-126, 2015.

[16] G. B. Juma and A. R. Yousif, "Size effect on the shear failure of high-strength concrete beams reinforced with basalt FRP bars and stirrups," Construction and Building Materials, vol. 209, pp. 77-94, 2019.

[17] J. Krassowska and M. Kosior-Kazberuk, "Experimental investigation of shear behavior of two-span fiber reinforced concrete beams," Archives of Civil Engineering, vol. 65, no. 2, pp. 35-55, 2019.

[18] B. Laurence, B. Estelle, and S. Michel, "Physicochemical characterisations of the bitumen-aggregate interface to get a better understanding of stripping phenomena," Road Materials and Pavement Design, vol. 14, no. 2, pp. 384-403, 2013.

[19] M. Peng and H. X. Huang, "Experimental study on basic mechanical properties of basalt fiber concrete," Concrete, vol. 1, pp. 74-75, 2012. 
[20] L. F. Zhang and Y. L. Yin, "Permanent deformation of asphalt pavement under horizontal moving load," Bulletin of the Chinese Ceramic Society, vol. 11, pp. 2834-2837, 2014.

[21] Y. H. Pi, Y. Li, Y. Pi, X. Y. Tan, and M. He, "Wetting model of asphalt on the aggregate surface and its effect factors," Advances in Materials Science and Engineering, vol. 2019, Article ID 4126464, 7 pages, 2019.

[22] J. L. Song and L. He, "BFRP bars as an alternative reinforcement of concrete structures-compatibility and adhesion issues," Advanced Materials Research, vol. 3903, pp. 233-241, 2015.

[23] T. Y. Liu and P. W. J. Zhang, "Compressive strength prediction of PVA fiber-reinforced cementitious composites containing nano- $\mathrm{SiO}_{2}$ using $\mathrm{BP}$ neural network," Materials, vol. 13 , no. 3, pp. 1-25, 2020.

[24] B. M. Wang and N. Tu, "Research progress of concrete mix design methods at home and abroad," Ready-Mixed Concrete, vol. 12, pp. 27-30, 2010.

[25] M. Cherrak, A. Bali, and K. Silhadi, "Concrete mix design containing calcareous tuffs as a partial sand substitution," Construction and Building Materials, vol. 47, pp. 318-323, 2013.

[26] Y. Wang, T. Zhang, C. Yan et al., "Effect of different loading systems on acousto-ultrasonic characteristics of concrete under axial compression," Materials Testing, vol. 61, no. 6, pp. 591-599, 2019.

[27] GBT50080-2016, Standard for Test Method of Performance on Ordinary Fresh Concrete, National Standards of the People's Republic of China, Beijing, China, 2016.

[28] S. Liu, J. Zhu, S. Seraj, R. Cano, and M. Juenger, "Monitoring setting and hardening process of mortar and concrete using ultrasonic shear waves," Construction and Building Materials, vol. 72, no. 72, pp. 248-255, 2014.

[29] J.M. Hu and J.Q Zhang, "Water transport in organic coatings: Fick diffusion process," Journal of Chinese Corrosion and Protection, vol. 22, no. 5, pp. 311-315, 2002.

[30] Z. W. Jiang and X. Xiao, "Study on the influence of vehiclebridge coupling vibration on the early performance of concrete," Concrete World, vol. 1, pp. 88-95, 2015.

[31] D. G. Manning, Effects of Traffic-Induced Vibrations on Bridge-Deck Repairs, Transportation Research Board, National Academy of Sciences, Washington, DC, USA, 1981.

[32] J. J. Wei, J. X. Xing, and Z. Fu, "The influence of bridge vibration caused by driving load on the performance of repaired concrete," Journal of Southeast University, vol. 40, no. 5, pp. 1057-1060, 2010.

[33] D. S. Ye and S. P. Shang, "Study on the influence of train vibration on the construction of railway bridge," Highway, vol. 9, pp. 20-24, 2001.

[34] N. Sabbağ and O. Uyanık, "Prediction of reinforced concrete strength by ultrasonic velocities," Journal of Applied Geophysics, vol. 141, pp. 13-23, 2017.

[35] D. H. Deng and Z. Q. Liu, "Research progress on sulfate crystal destruction theory," Journal of the Chinese Ceramic Society, vol. 40, no. 2, pp. 175-185, 2012.

[36] GBT 50082-2009, Standard for Test Methods of Long-Term Performance and Durability of Ordinary Concrete, National Standards of the People's Republic of China, Beijing, China, 2009.

[37] F. G. Leng, X. X. Ma, and G. F. Tian, "Test method for sulfate resistance of concrete," Journal of Southeast University (Natural Science Edition), vol. 27, no. s2, pp. 45-48, 2006.
[38] K. N. Jallad, M. Santhanam, and M. D. Cohen, "Stability and reactivity of thaumasite at different $\mathrm{pH}$ levels," Cement and Concrete Research, vol. 33, no. 3, pp. 433-437, 2003.

[39] Q. X. Zhao, D. H. Li, and G. L. Yan, "Resistance to sulfate corrosion of damaged concrete," Journal of the Chinese Ceramic Society, vol. 40, no. 2, pp. 217-220, 2012.

[40] C. Ferraris, P. Stutzman, M. Peltz, and J. Winpigler, "Developing a more rapid test to assess sulfate resistance of hydraulic cements," Journal of Research of the National Institute of Standards and Technology, vol. 110, no. 5, pp. 529540, 2005.

[41] S. P. Chen and J. W. Wang, "Research on damage model of fiber concrete in freeze-thaw environment," Concrete, vol. 10, pp. 58-61, 2017. 